carefully at our recommendation," says Volberding of the HIV guidelines. "The committee really was independent in its deliberations."

Critics say that the influence exerted by industry money is unconscious but powerful. Funding for conference travel and accommodation has been linked with increased requests for a sponsor's drug, for example. And meetings with drug reps both decrease physicians' ability to spot erroneous claims about medications and increase their requests for new drugs with no demonstrated advantage over generics (A. Wazana J. Am. Med. Assoc. 283, 373-380; 2000).

"It's not true that people can remain completely objective," says Peter Gøtzsche, director of the Nordic Cochrane Centre in Copenhagen, Denmark, which runs independent reviews of drug efficacy.

Gøtzsche and others want guidelines to be prepared in ways that reduce the potential for bias. Some such schemes already exist. In Britain, for example, guidelines are provided by a government-funded body called the National Institute for Health and Clinical Excellence (NICE). Although some of the experts used by NICE have industry links, the institute itself is independent of industry and consults with other stakeholders, such as patients' groups.

\section{Expert witnesses}

In the United States an alternative process is being used for conditions where there is conflicting evidence as to the best treatment. Experts in a particular condition - those most likely to have relevant industry links are used as witnesses, but the panel members themselves are chosen for their skills at examining medical data. "If you have a conflict of interest you can't be on the panel," says Susan Rossi, deputy director of the Office of Medical Applications of Research at the National Institutes of Health, which runs the scheme.

But the bodies that produce guidelines maintain that there just aren't enough experts without conflicts of interest. Nathaniel Clark of the American Diabetes Association estimates that three-quarters of members eligible to write guidelines have industry links, and other organizations report a similar number.

The latest figures underline the urgency of breaking the deadlock. In 2002, Choudhry and colleagues found similar levels of conflicts of interest, but he says that physicians have since assumed that disclosing conflicts is all that is required to solve the problem. With drugcompany stock-holders still sitting on the panels that make prescription decisions, Choudhry warns: "We need a better way to deal with conflicts of interest."

Rosie Taylor and Jim Giles

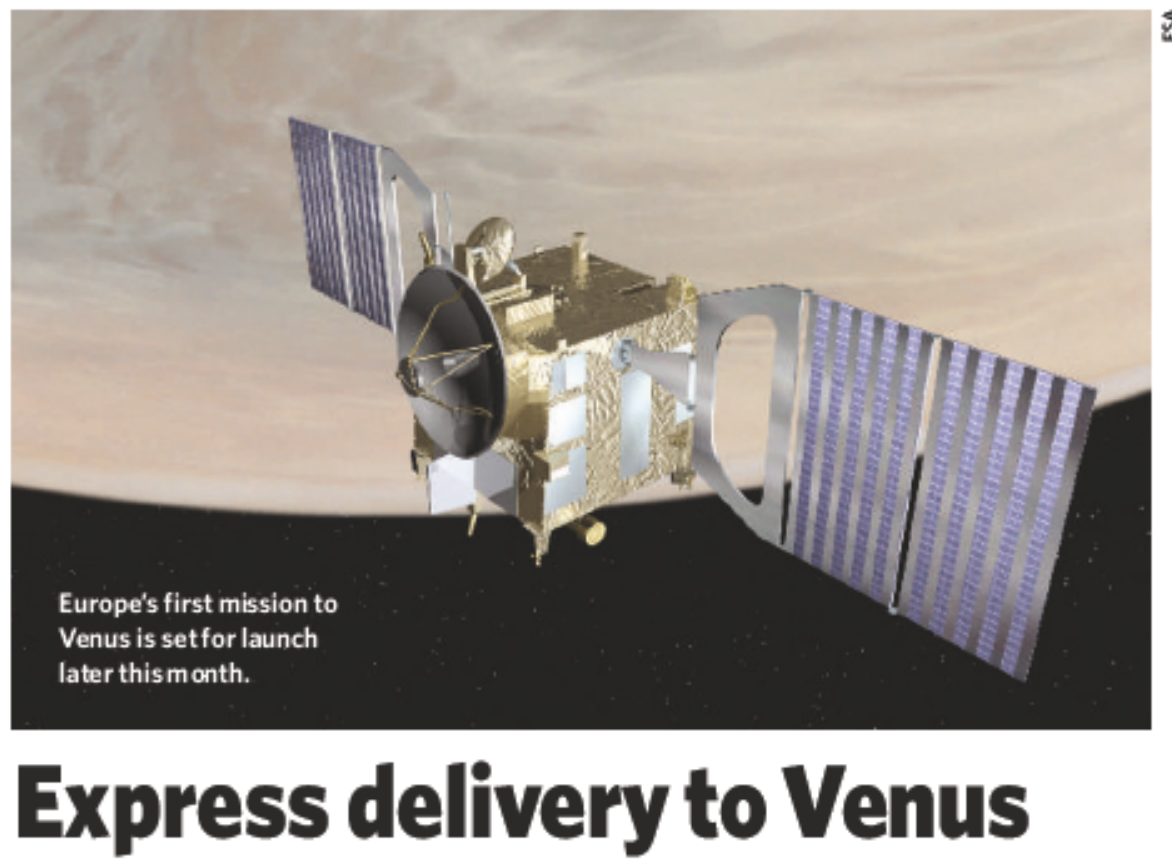

Get set for a revival of interest in Earth's wayward twin. The European Space Agency (ESA) plans to launch Venus Express next week - the first visit to the planet in more than a decade. The focus of the $€ 220$-million (US\$265-million) mission will be the planet's thick atmosphere, which some think could host exo tic life forms that use ultraviolet instead of visible light.

Venus Express will begin its journey from Kazakhstan on a Soyuz-Fregat rocket; the month-long launch window opens on 26 October. ESA developed the mission - its first to Venus - in less than four years, after asking the science community for ideas on adapting its Mars Express spacecraft for another purpose.

The craft uses cameras and spectrometers adapted from Mars Express and Rosetta, an upcoming comet mission. These will build up a three-dimensional profile of Venus's carbon dioxide-rich atmosphere, which traps heat and drives temperatures on the surface to a searing $450^{\circ} \mathrm{C}$. Past missions, including the 1978 Pioneer Venus orbiter and the Magellan surface-mapper of the 1990s, have hinted at active volcanism and lightning on the planet; Venus Express will investigate these observations further.

The mission may also help to determine what is absorbing ultraviolet radiation in the planet's clouds. David Grinspoon of the Southwest Research Institute in Boulder, Colorado, and others speculate that life may have evolved that thrives in acidic environments and photosynthesizes ultraviolet light. Rather than living on the hot surface, such organisms might reside in long-lived clouds, where temperatures and pressures are more Earth-like.

Grinspoon has been modelling the history of Venus's atmosphere, and his preliminary results indicate that the planet's early ocean could have persisted for as long as 2 billion years. Life could have adapted to the clouds when the surface water disappeared, he suggests.

Grinspoon calls this a kind of "thought experiment", and does not claim there is evidence for life on Venus today. Nor does he believe that terrestrial microbes stowing away on Venus Express risk contaminating the planet. Current international guidelines for planetary protection require sterilization for Mars-bound spacecraft, but not for tho se headed for hot and acidic Venus.

Still, NASA has asked the US National Academy of Sciences, based in Washington DC, to revisit the subject of planetary protection for Venus. Thirty years have passed since it last looked at the question, says NASA planetary-protection officer John Rummel. At present, the agency is mulling over ideas for samplereturn missions to Venus, and the academy has recommended that a lander be sent to the planet in the next decade.

In the meantime, Japan plans to launch its Venus Climate Orbiter in 2008, and two Mercury-bound spacecraft MESSENGER and BepiColombo - will study Venus during brief fly-bys. Tony Reichhardt 